УДК 577.2

DOI: 10.33184/spbgb-2021-09-21.27

\title{
Влияние внеклеточного матрикса на активность транскрипци- онного фактора эпителиально-мезенхимального перехода Zeb1 при раке молочной железы
}

\author{
(C) А.П. Лобода ${ }^{1 *}$, Н.А. Барлев ${ }^{1,2}$ \\ ${ }^{1}$ Московский Физико-Технический Институт \\ Долгопрудный, 141701, Россия \\ ${ }^{2}$ Институт иитологии РАН \\ Санкт-Петербург, 194064 Россия \\ *Email: a-p-loboda@yandex.ru
}

Метастазирование является лидирующей причиной смертности от рака молочной железы. Известно, что ключевую роль в метастазировании играет эпителиальномезенхимальный переход (ЭМП). Процесс ЭМП подвергается сложному, многоуровневому регулированию, в том числе с помощью транскрипционных фракторов, важнейшим из которых является Zeb1. Известно, что при ЭПМ происходит взаимная регуляция раковых клеток и внеклеточного матрикса (ВКМ). Работа посвящена поиску возможных молекулярных механизмов, лежащих в основе кооперации между Zeb1 и BKM при регуляции экспрессии генов в раке молочной железы.

Ключевые слова: рак молочной железы, эпителиально-мезенхимальный переход, транскрипционный фрактор Zeb1, метастазирование.

Рак молочной железы (РМЖ) - одно из наиболее часто диагностируемых злокачественных онкологических заболеваний. Примерно 15-20\% всех случаев РМЖ составляет трижды негативный молекулярный подтип. Он характеризуется существенно более слабым ответом на химиотерапию или гормональную терапию по сравнению с другими типами РМЖ, а также худшим клиническим прогнозом и высокой риском метастазирования [1].

Литературные данные свидетельствуют о том, что одной из основных причин метастазирования и возникновения резистентности к терапии при РМЖ является эпителиально-мезенхимальный переход (ЭПМ) [2][3]- обратимая генетическая программа, реализуемая в процессе эмбрионального развития и патологически активируемая при раке. Этот процесс сопровождается потерей межклеточных контактов, реорганизацией цитоскелета, а также повышенной подвижностью клеток и устойчивостью к терапии [4]. Программа ЭМП контролируется несколькими группами транскрипционных фракторов (ЭМП-ТФ), среди которых Zeb1 - ключевой. Он играет центральную роль в осуществлении эпителиально-мезенхимального перехода [5].

Литературные данные свидетельствуют о том, что Zeb1-индуцированный ЭМП вовлечен во взаимное регулирование раковых клеток и внеклеточного матрикса (ВКМ), способствующее инвазии и метастазированию [6]. Также известно, что Zeb1 может участвовать в регуляции транскрипции генов, отвечающих за репарацию ДНК, вызывая устойчивость к противоопухолевой терапии [7]. Поиск возможных механизмов, лежащих в основе кооперации между Zeb1 и ВKM при регуляции транскрипции генов, ответственных за репарацию ДНК, важен для более полного понимания процессов, проис- 
ходящих при РМЖ, что в дальнейшем позволит значительно улучшить существующую терапию этого заболевания.

В настоящей работе методами иммуноблоттинга и ОТ-ПЦР было показано влияние коллагена I типа, как модели BKM, на Zeb1-зависимую регуляцию экспрессии гена BRCA2, одного из ключевых участников гомологической репарации ДНК.

В работе использованы следующие клеточные модели:

- MCF-7 - клеточная линия РМЖ эпителиального типа. Так как в норме эта клеточная линия не экспрессируют Zeb1, с помощью лентивирусной трансдукции в них была введена индуцибельная система Tet-ON для эктопической экспрессии Zeb1 в ответ на обработку клеток доксициклином.

- $\quad$ MDA-MB-231 - клеточная линия РМЖ мезенхимального типа, в норме содержащая Zeb1 дикого типа.

- $\quad$ MDA-MB-231 Zeb1 KO - клеточная линия РМЖ мезенхимального типа с нокаутом Zeb1. Нокаут осуществлялся помощью лентивирусной трансдукции векторной конструкции, содержащей малые шпильковые PHK к Zeb1.

Для того, чтобы изучить влияние коллагена I типа на активность Zeb1, культуральные чашки покрывали стерильным водным раствором коллагена I типа различных концентраций (1 мг/мл и 2 мг/мл). Затем указанные выше клеточные линии инкубировали на коллагеновых чашках в течение трех дней (чашки без коллагена использовались в качестве негативного контроля). В клеточной линии MCF-7 экспрессию Zeb1 индуцировали с помощью добавления 1 мкг/мл доксициклина в среду в течение двух дней.

Данные ОТ-ПЦР показали, что индукция экспрессии Zeb1 в эпителиальных клетках PMЖ MCF-7, вызывала подавление транскрипции BRCA2 независимо от присутствия коллагена при любой его концентрации (рис.1).

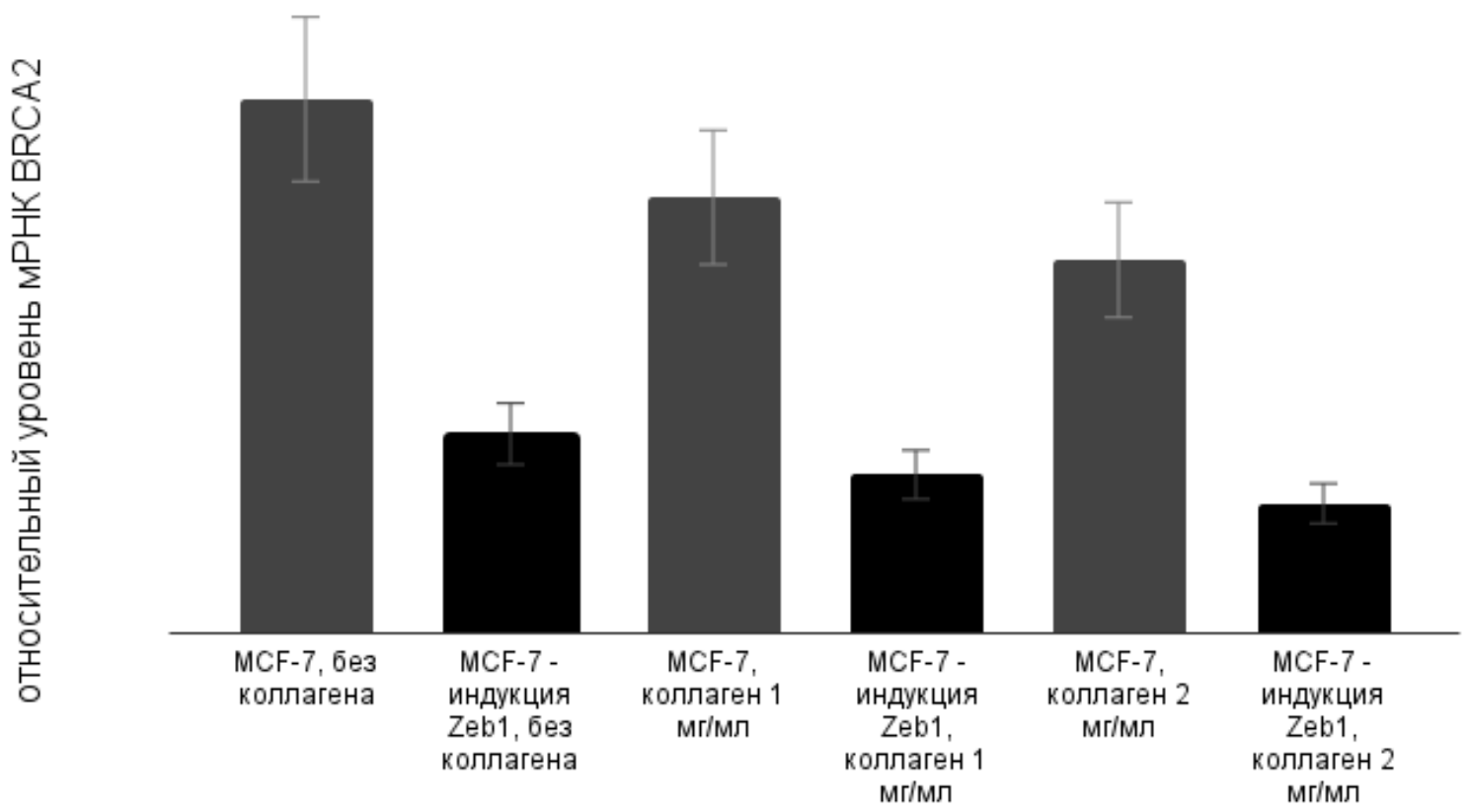

Рис.1. Данные ОТ-ПЦР, демонстрирующие изменение относительно контроля уровня мPHK BRCA2 в клетках MCF-7, инкубированных на обработанных коллагеном культуральных чашках. В качестве контроля использовались клетки MCF-7, инкубированные на чашке без коллагена и без индукции Zeb1. 
В мезенхимальных клетках PMЖ MDA-MB-231 подавление экспрессии эндогенного Zeb1 приводило к восстановлению экспрессии BRCA2, также независимо от коллагена (рис. 2).

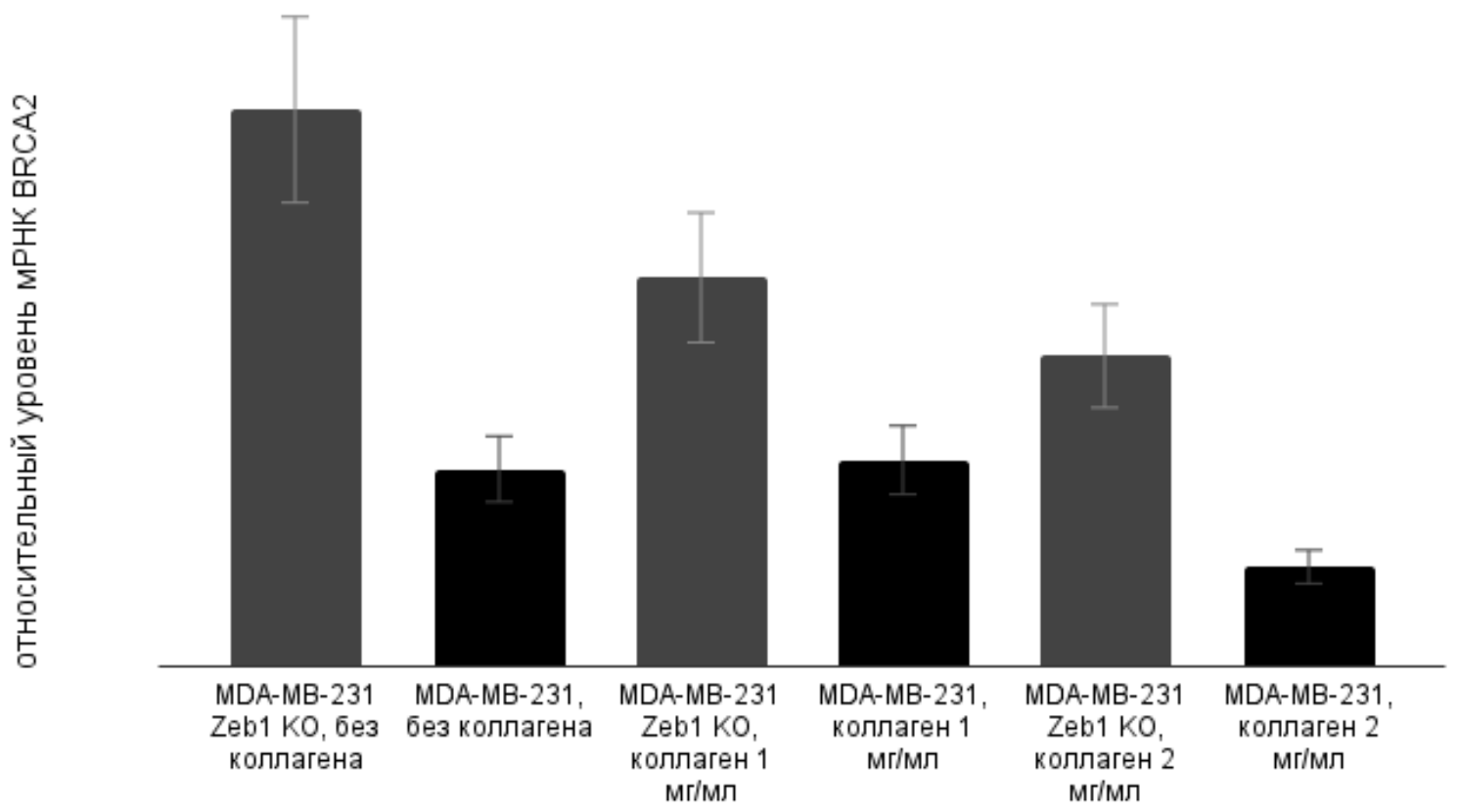

Рис. 2. Данные ОТ-ПЦР, демонстрирующие изменение относительно контроля уровня мPHK BRCA2 в клетках MDA-MB-231 и MDA-MB-231 Zeb1 KO, инкубированных на обработанных коллагеном культуральных чашках. В качестве контроля использовались клетки MDA-MB-231 Zeb1 KO, инкубированные на необработанной коллагеном культуральной чашке.

Данные иммуноблоттинга показали значительное различие между клетками MCF-7 и MDA-MB-231 в эфффекте, оказываемом Zeb1 и коллагеном на количество белка BRCA2. Нам удалось показать, что белковый уровень BRCA2 зависит от коллагена гораздо сильнее, чем от Zeb1. В присутствие коллагена в мезенхимальных клетках PMЖ MDAMB-231, содержащих Zeb1 дикого типа, происходит быстрая деградация BRCA2 по сравнению с клетками MDA-MB-231 KO (рис. 3). 
MDA231

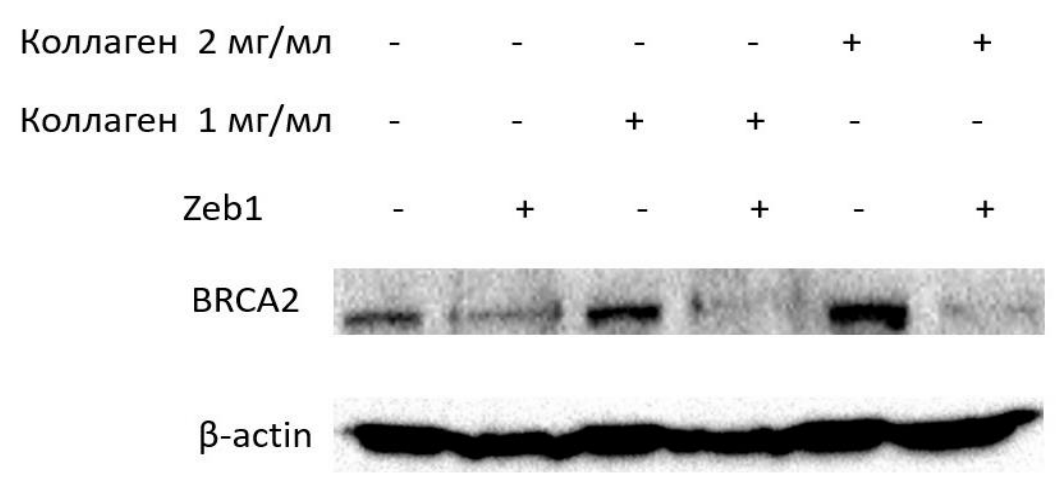

Рис. 3. Результаты иммуноблоттинга в клеточных линиях MDA-MB-231 и MDA-MB-231 Zeb1 KO, инкубированных в течение трех дней на культуральных чашках, обработанных растворами коллагена I типа различных концентраций.

Однако в эпителиальных клетках MCF-7 индукция экспрессии Zeb1 в присутствии коллагена, напротив, приводит к стабилизации BRCA2 (рис. 4).

\section{MCF7}

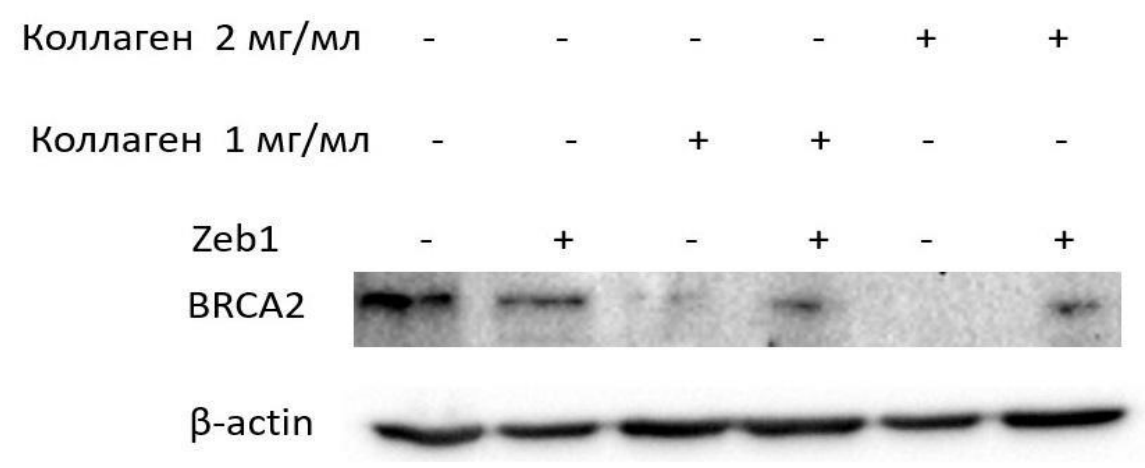

Рис. 4. Результаты иммуноблоттинга в клеточной линии MCF-7, инкубированной в течение трех дней на культуральных чашках, обработанных растворами коллагена I типа различных концентраций.

Данные ОТ-ПЦР позволяют утверждать, что Zeb1 ингибирует экспрессию BRCA2 в обеих использованных клеточных линиях РМЖ. В дальнейших экспериментах следует установить, является ли этот эффрект результатом действия Zeb1 непосредственно как 
транскрипционного репрессора, так как подобная активность хорошо описана для этого белка [8].

Данные иммуноблоттинга показали, что белковый уровень BRCA2 зависит от коллагена гораздо сильнее, чем от Zeb1. Полученные результаты также указывают на различный механизм кооперации Zeb1 и коллагена в мезенхимальной клеточной линии MDAMB-231 и эпителиальной MCF-7. В первом случае независимо от коллагена всех используемых концентраций активация Zeb1 приводила к значительному уменьшению количества белка BRCA2, что согласуется с данными ОТ-ПЦР и предполагает Zeb1зависимую регуляцию транскрипции гена BRCA2. Однако в эпителиальной клеточной линии MCF-7 присутствие Zeb1 и коллагена, напротив, приводила к заметной стабилизации белка BRCA2, что предполагает наличие иного молекулярного механизма регуляции уровня BRCA2. Полученные данные, безусловно, требуют дальнейших исследований. Однако, так как в клетках MDA-MB-231 ген Tp53 несет доминантнонегативную мутацию R280K, а в MCF-7 присутствует p53 дикого типа [9], можно предположить, что р53, один из важнейших участников репарации ДНК, каким-то образом участвует в регуляции данного сигнального пути.

Работа выполнена при фринансовой поддержке гранта РНФ 20-15-00189.

\section{Литература}

1. Поздняков Д.Ю., Шувалов О.Ю., Барлев Н.А., Миттенберг А.Г. Транскрипционный фактор Zeb1: посттранскрипционная регуляция его активности в карциномах молочной железы человека // Цитология. - 2020. - Т. 62. - №. 1. - С. 3-15.

2. Wang Y., Zhou B. P. Epithelial-mesenchymal transition in breast cancer progression and metastasis //Chinese journal of cancer. - 2011. - T. 30. - №. 9. - C. 603.

3. Gooding A. J., Schiemann W. P. Epithelial-Mesenchymal Transition Programs and Cancer Stem Cell Phenotypes: Mediators of Breast Cancer Therapy Resistance //Molecular Cancer Research. - 2020. - T. 18. - №. 9. - C. 1257-1270.

4. Lamouille S., Xu J., Derynck R. Molecular mechanisms of epithelial-mesenchymal transition //Nature reviews Molecular cell biology. - 2014. - T. 15. - №. 3. - C. 178-196.

5. Zhang P., Sun Y., Ma L. ZEB1: at the crossroads of epithelial-mesenchymal transition, metastasis and therapy resistance //Cell cycle. - 2015. - T. 14. - №. 4. - C. 481-487.

6. Peng D. H. et al. ZEB1 induces LOXL2-mediated collagen stabilization and deposition in the extracellular matrix to drive lung cancer invasion and metastasis //Oncogene. -2017. - T. 36. - №. 14. - C. 1925-1938.

7. Zhang P. et al. ATM-mediated stabilization of ZEB1 promotes DNA damage response and radioresistance through CHK1 //Nature cell biology. - 2014. - T. 16. - №. 9. - C. 864875.

8. Madany M., Thomas T., Edwards L. A. The Curious Case of ZEB1 //Discoveries. 2018. - T. 6. - №. 4.

9. Liu J. et al. The Expression of p53 Tumor Suppressor Gene in Breast Cancer Cell Is Down-Regulated by Cytokine Oncostatin M //Cell Growth and Differentiation-Publication American Association for Cancer Research. - 1999. - T. 10. - №. 10. - C. 677-684. 


\title{
Effect of extracellular matrix on the activity of the epithelial-mesenchymal transition
} transcription factor Zeb1 in breast cancer cells

\author{
A.P. Loboda ${ }^{1 *}$, N. A. Barlev ${ }^{1,2}$ \\ ${ }^{1}$ Moscow Institute of Physics and Technology, Dolgoprudny, 141701, Russia. \\ ${ }^{2}$ Institute of Cytology of the Russian Academy of Science, St-Petersburg, 194064. Russia. \\ *Email:a-p-loboda@yandex.ru
}

Metastasis is the leading cause of death caused by breast cancer. It is known that the key role in metastasis is played by the epithelial-mesenchymal transition (EMT). The EMT process undergoes complex regulation on different levels involving several transcription factors, the most important of which is Zeb1. It is known that during EMT there is a mutual regulation of cancer cells and the extracellular matrix (ECM). The present work is focused on the search for possible molecular mechanisms underlying the cooperation between Zeb1 and ECM in the regulation of gene expression in breast cancer.

Key words: breast cancer, epithelial-mesenchymal transition, Zeb1 transcription factor, metastasis 